\title{
Inheritance of the acoustic signal characters in interspecific hybrids of bank (Clethrionomys glareolus) and tianshan (C. centralis) voles
}

\author{
M. Rutovskaya \\ A.N. Severtsov Institute of Ecology and Evolution RAS, Moscow, Russia \\ e-mail: desmana@yandex.ru
}

Key words: sound communication, rodents, inheritance

\begin{abstract}
Motivation and Aim: The continuity of behavioral responses in the traits of generation can be interpreted ambiguously, because animal behaviour can be transmitted from generation to generation genetically or can be trained. Genetic inheritance of sound characteristics in mammals has been shown by a number of authors, for example, in common [1] or bank voles [2], and it can also correlate with the inheritance of morphological features of the species [3]. The study of inheritance of the sound signals characteristics in the absence of directional selection is of particular interest, and that was the purpose of the present work.
\end{abstract}

Methods and Algorithms: Comparisons of distress signals of hybrids, born of TienShan voles females (C. centralis) from Kyrgyzstan and bank vole males from the Tver region (C. glareolus suecicus) and the sounds of the parent species were made. Distress signals of voles were recorded in laboratory, using a Tascam NoDA-P1 professional digital tape recorder (United States) and SENNHEISER K6 microphone (Germany). Sounds were analyzed using the AviSoft SASLab pro professional program (version 4.2). To perform the spectral analysis of signals in building spectrograms, a fast Fourier transform length of 512 points and an overlap of $100 \%$ for the frequency axis and $88 \%$ for the temporal axis were used. Acoustic signals of the hybrids and parent forms were compared using the variance and discriminant analysis.

Results: The distress signals of the TienShan voles were shorter and the dominant frequency had lower values than in the signals of the bank voles. The dominant frequency of hybrids signals was closer to that of the bank voles. However, the duration of the hybrids sounds, on the contrary, is closer to that of the TienShan voles. The expression of the noise component in the sounds of the hybrids occupies an intermediate position. The discriminant analysis of distress signals in the the TienShan and bank voles showed $93 \%$ of correct attributions.

Conclusion: The hybrids signals were different from the sounds of parental species by its characters. The father's genome (bank voles) has had great influence on characters of the sound signals in hybrids.

Acknowledgements: Supported by the RFBR (16-04-00149)

\section{References}

1. Frank F. (1967) Twittering - a voice mutation in Microtus. Heredity. 22(4):607-610.

2. Rutovskaya M.V., Osipova O.V., Soktin A.A. (2017) Acoustic signal characters in interspecific hybrids of bank and red-backed voles. Biology Bulletin. 44(3):296-306.

3. Nikol'skii A.A. (1984) Acoustic signals of mammals in the evolutionary process. Moscow: Nauka. 